\title{
Cyber-physical-system-based smart water system to prevent flood hazards
}

Tsun-Hua Yang ${ }^{1,2}$, Sheng-Chi Yang ${ }^{1}$, Hong-Ming Kao ${ }^{1 *}$, Ming-Chang $\mathrm{Wu}^{1}$ and Hao-Ming Hsu ${ }^{3}$

\author{
* Correspondence: hmkao@narlabs. \\ org.tw \\ ${ }^{1}$ Taiwan Typhoon and Flood \\ Research Institute, National Applied \\ Research Laboratories, 11F, No. 97, \\ Sec. 1, Roosevelt Rd, Taipei 100, \\ Taiwan \\ Full list of author information is \\ available at the end of the article
}

\begin{abstract}
Background: Extreme weather and climate events such as super typhoons and unprecedented recorded high intensity rainfall events have increased in recent years due to climate change. Such extreme weather events generate floods and cause loss of life and property. Therefore, efficient strategies and measures for flood mitigation and prevention are essential. Computer-aided techniques can increase the speed of emergency response and reduce the impacts of a flood.

Methods: This study applied the cyber-physical system concept to develop a smart flood information system, called Dayu Smart Water System. The system includes an on-site monitoring network and software for rapid flood modeling to provide updated information. With the utilization of Internet of Things and artificial intelligence, the system not only provides forecast information but also plays an active role by enabling users to take emergency response measures before, during, and after a flood. The system is aimed at accelerating emergency responses during a flood without requiring any human intervention.

Results: The system was deployed in a high-tech industrial park in central Taiwan. Experimental results revealed that the system could increase the response efficiency of the emergency operations center during a few extreme events in 2017. To enable the system to respond to a wide range of flood induced threats in a more effective manner, a few advanced functions are under development and discussed in this paper.

Conclusions: This study utilized Dayu Smart Water System that integrates on-site monitoring sensors and advanced modeling tools to provide optimal flood forecasts. However, the proposed system has implemented only the first three levels - connection, conversion, and cyber levels. The higher the number of levels is, the more added value is the system provides. The fourth and fifth levels, namely the cognition and configuration levels, were not discussed in the study. Further developments in these two levels will be conducted.
\end{abstract}

Keywords: Cyber-physical system, Internet of things, Artificial intelligence, Flood warning

\section{Background}

Various disasters such as typhoons, floods, and earthquakes may occur simultaneously and cause catastrophic loss of life and property. In certain scenarios, disasters can be sequential, in that the first disaster may trigger the second one, which may trigger subsequent disasters (EISNER, 2014). Historical events such as the Thailand flood in 2011 and Fukushima Daiichi nuclear disaster in 2011 are examples of such scenarios. For

(c) The Author(s). 2018 Open Access This article is distributed under the terms of the Creative Commons Attribution 4.0 International License (http://creativecommons.org/licenses/by/4.0/), which permits unrestricted use, distribution, and reproduction in any medium, provided you give appropriate credit to the original author(s) and the source, provide a link to the Creative Commons license, and indicate if changes were made. 
example, the Thailand flood in 2011 caused over hundreds of deaths, and millions of people were affected. The economic damage was estimated to be over US $\$ 40$ billion, according to a World Bank survey (Mahul, 2017). Taiwan is located in the northwestern Pacific Ocean and is struck by typhoons three to four times a year. Typhoon Morakot in 2009 is another example of such scenarios. This typhoon first engendered a considerable amount of rainfall and subsequently triggered large-scale landslides, resulting in more than hundreds of deaths in the south of Taiwan. Extreme weather and climate events such as super typhoons and unprecedented high-intensity rainfall events will attract more attention in the future because of the impact of climate change. Structural measures, including the construction of structures such as dams and river bifurcation, are proven to be effective for flood mitigation. However, the failure of structural measures may cause greater disasters. Nonstructural measures such as early warning systems can enable first responders to take necessary actions for reducing damage and losses. Most early warning systems only provide passive information such as flood forecasts or real-time observations (Thielen et al., 2009; Lopez-Trujillo, 2010; Yang et al., 2015).

The rapid development of artificial intelligence (AI) and Internet of Things (IoT) can transform early warning systems from passive information provides to active systems that implement necessary actions during a disaster. AI has been applied to disaster forecasting, prevention, and mitigation. For example, Augello et al. (2016) used an agent model and a monitoring network to propose preventive measures and provide alerts before the occurrence of an event. A chatbot was created at the front end of the system to interact with users. Various studies have proved that AI can accelerate complicated processes and generate efficient solutions not only in disaster-related fields but also in many other fields (e.g., Monostori 2003; Alemdar et al., 2017). IoT was introduced in 2005 and is mostly applied to supply chain management, environmental monitoring, and other nonstress environments. Yang et al. (2015) identified that the IoT technology can match identified information requirements and provide added value to emergency response operations in terms of obtaining efficient cooperation, accurate situational awareness, and complete resource visibility. Therefore, this study utilized AI and IoT to develop a cyberphysical-system (CPS)-based smart water system-called Dayu Smart Water System (DayuSWS) - that integrates on-site monitoring sensors and advanced modeling tools to provide optimal flood forecasts. In addition, the system analyzes all the collected information and forecasts to trigger active actions based on the situation; for example, the system controls the start or stop function of water pumps. The remainder of this paper is organized as follows. Study area section briefly describes the study area in which the system was deployed. Components of the CPS-based smart flood information system section explains the concept of a CPS and its application in the study. Case and discussion section presents the case study and discussion. Finally, Conclusions section concludes the paper.

\section{Study area}

The Huawei Science Park, located in central Taiwan, was selected as the study area. The red line shows the boundary of the park in Fig. 1. The yellow circles and the blue arrows indicate the water level gauge locations and the flow direction, respectively. The 


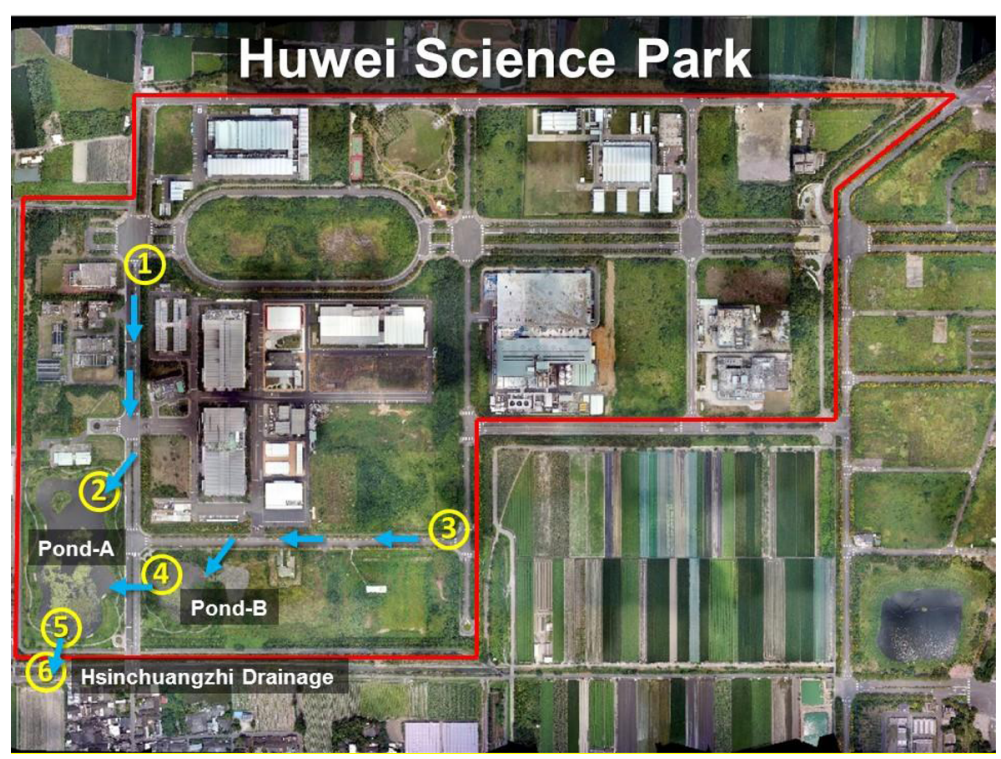

Fig. 1 Study area-Huawei Science Park

DayuSWS was deployed in the park to conduct observations, provide forecasts, and take actions. The park has an area of approximately 97 ha and has six optoelectronic and biotechnological manufactories. The land is characterized by a gently sloped surface from the northeast toward the southwest, with the average slope being 0.002 . Storm water is stored in detention ponds before its release to the river, because of current legal restrictions. Therefore, two detention ponds, namely pond $\mathrm{A}$ and pond $\mathrm{B}$, were set at the lowest point of the Huawei Science Park to store flood water for a period of 50 years (designed rainfall intensity: $101.8 \mathrm{~mm} / \mathrm{h}$ ), as illustrated in Fig. 1. The drainage system collects all the rain water within the Huawei Science Park and eventually transfers it to pond $\mathrm{A}$. The storm water in pond $\mathrm{A}$ is released only if the water level in this pond is higher than that of the Hsinchuangzhi drainage (please find the location in Fig. 1). During Typhoon Kong-rey in 2013, the water level in pond A was approximately $20 \mathrm{~m}$ (maximum water level: $20.56 \mathrm{~m}$ ), implying that flooding risk still exists because of climate change and developments in the area. In addition, on September 26, 2016, a $5 \times 5 \mathrm{~m}^{2}$ digital surface model (DSM) was obtained using an unmanned aerial vehicle (UAV) with enhanced GPS technology. This DSM information was used to develop all subsequent models and conduct all simulations.

\section{Methods}

\section{Components of the CPS-based smart flood information system}

A 5C architecture-a connection level, conversion level, cyber level, cognition level, and configuration level (Fig. 2) -was used as the guideline to achieve CPS (Lee et al., 2015), one of crucial technologies of industry 4.0. Monostori et al. (2016) mentioned that CPS is one of the most notable advances in the development of computer science and information and communication technologies. Moreover, CPS are broadly applied in manufacturing, decision-making, and energy-related industries 


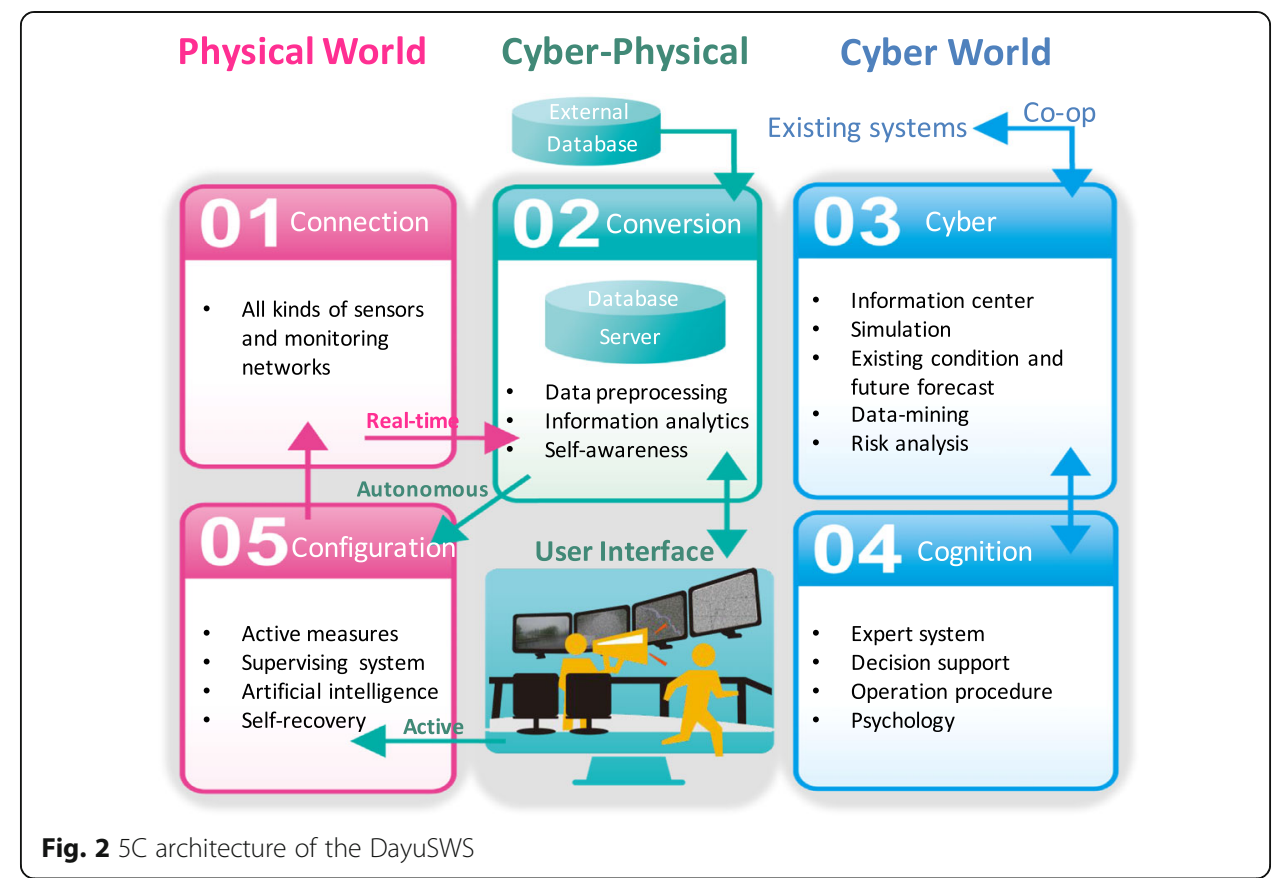

(Rho et al., 2016). This study developed an innovative CPS-based smart water system, called DayuSWS, that bridges the gap between the physical world and cyberspace. On-site sensors and a monitoring network record observations in real time and transfer the observations to a big-data platform (connection to conversion level). The field observations are standardized after data preprocessing and are sent to the DayuSWS as inputs for model simulation (conversion to cyber level). The DayuSWS can be integrated with other existing systems or a decision support system (cyber to cognition level) to trigger appropriate active disaster mitigation measures (cognition to configuration levels).

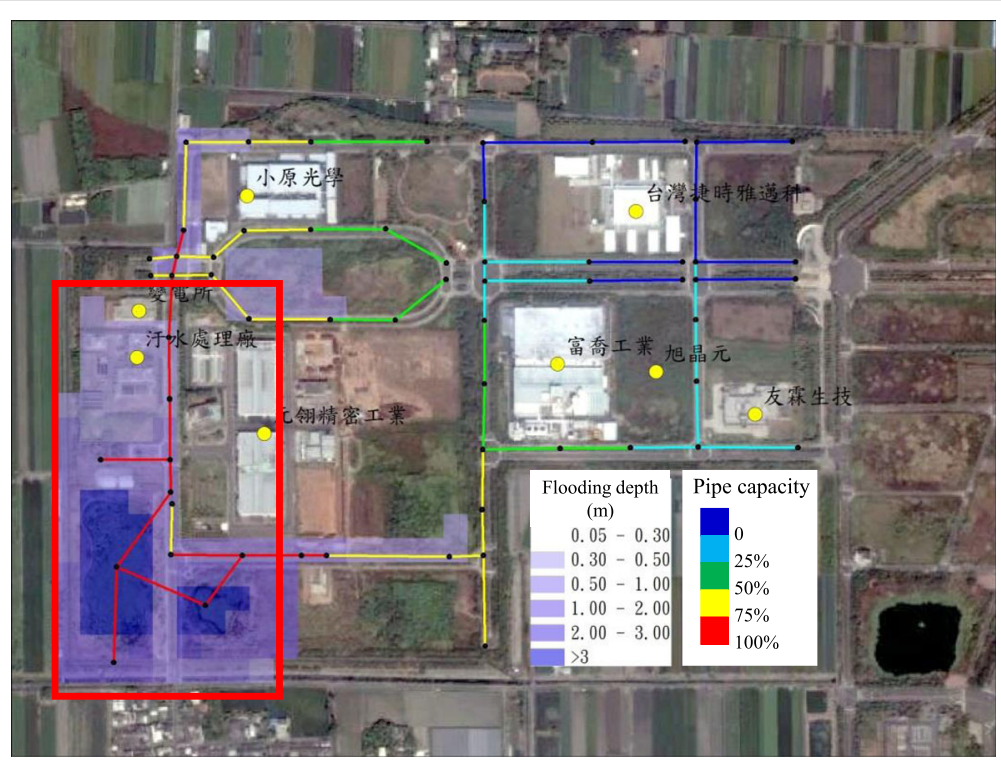

Fig. 3 Scenario involving rainfall for $3 \mathrm{~h}$ and 150-mm accumulated water to identify the high-flood-risk area 


\section{Connection level}

The connection level comprises the on-site sensors. Various types of sensors were installed on the basis of the study's requirements. The connection level is the first level of the DayuSWS that initiates all system functions. Therefore, the information recorded by this level is crucial to trigger the other levels. The sensors were set up after carefully analyzing the locations to ensure that the collected information is suitable. A scenario involving rainfall for $3 \mathrm{~h}$ and 150-mm accumulated rain water, with no water outflow from the park, was considered in this study. The simulated results are presented in Fig. 3. The results revealed the west side of the park to have a high risk of flooding, which is consistent with the topology of the area. Because all the vital facilities such as power and water treatment plants are located on the west side of the park, a total of six water gauges were installed on this side, as shown in Fig. 1. Figure 4 is the pictures of all on-site gauges: the gauge locations from left to right and beginning at the top correspond to the numbered locations in Fig. 1. Gauges 5 and 6 were installed to monitor the water levels in pond $\mathrm{A}$ and the Hsinchuangzhi drainage, respectively, and are crucial to understanding the water exchange between the park and outside area. Gauge four was installed to monitor the water level in pond B. The rain water collected on the east side is monitored by gauge three and then transferred to pond B. Moreover, gauges one and two were installed to monitor the water collected on the upper side of the park (red rectangle in Fig. 3). A rainfall gauge was installed at location 6 to monitor the park's rainfall. The real-time observations of all the sensors are wirelessly transferred to the big-data platform at an interval of $10 \mathrm{~min}$.

\section{Cyber level}

The connection and conversion levels transform real-time observations to useful information for decision-makers. The information obtained is highly accurate because it is based on on-site observations. However, information with an adequate lead time could not be provided. Therefore, the cyber level is employed to provide forecasts with a longer lead time. In this study, the cyber level was determined to provide flood forecasts
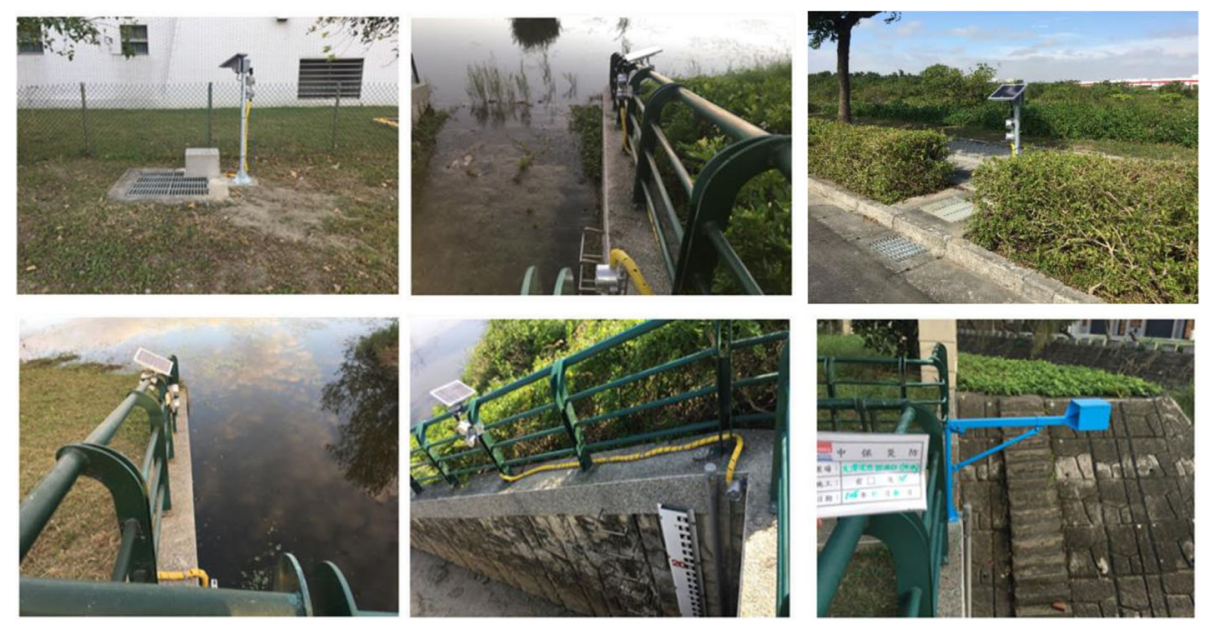

Fig. 4 On-site water gauges set up at particular locations 
with a lead time of $6 \mathrm{~h}$. To obtain the forecasts, a 1D-1D dual drainage model was included, with rainfall forecasts in numerical format serving as the model input. The details are discussed in the following subsections.

\section{Numerical rainfall forecasts}

To provide more reliable and timely flood forecasts, rainfall forecast information is crucial. In this study, high-resolution numerical rainfall forecast information from an ensemble numerical weather prediction system in Taiwan was used. The ensemble numerical weather prediction system fabricated by the Taiwan Typhoon and Flood Research Institute (TTFRI) consists of more than 20 ensemble units that are individual numerical weather prediction models with different model configurations. Therefore, a collection of more than 20 numerical rainfall forecasts can be obtained from this system for the same location and time. This system collects worldwide observation data such as temperature, wind, surface pressure, and relative humidity from satellites, atmospheric sounding devices, buoys, aviation routine weather reports, ships, and other available sources. The collected data are then used as boundary or initial conditions for the ensemble units. Then, rainfall forecasts in numerical format are generated according to these real-time weather conditions. The ensemble system aims to provide 72-h numerical rainfall forecasts and generates four runs per day at a 5-km spatial resolution. Hsiao et al. (2012, 2013), Yang et al. (2015), and Wu and Lin (2017) have provided additional details on the ensemble numerical weather prediction system. Moreover, a statistical technique for effectively integrating ensemble forecasts is applied in the proposed system to improve the accuracy of 1 - to $24-\mathrm{h}$ rainfall forecasts. Through an artificial neural network (ANN)-based statistical technique, more than 20 ensemble rainfall forecasts are integrated to yield one accurate rainfall forecast. Our preliminary experiments revealed that improved 24-h rainfall forecasts were obtained through the ANN-based integration technique (Wu et al., 2016). Moreover, to further improve

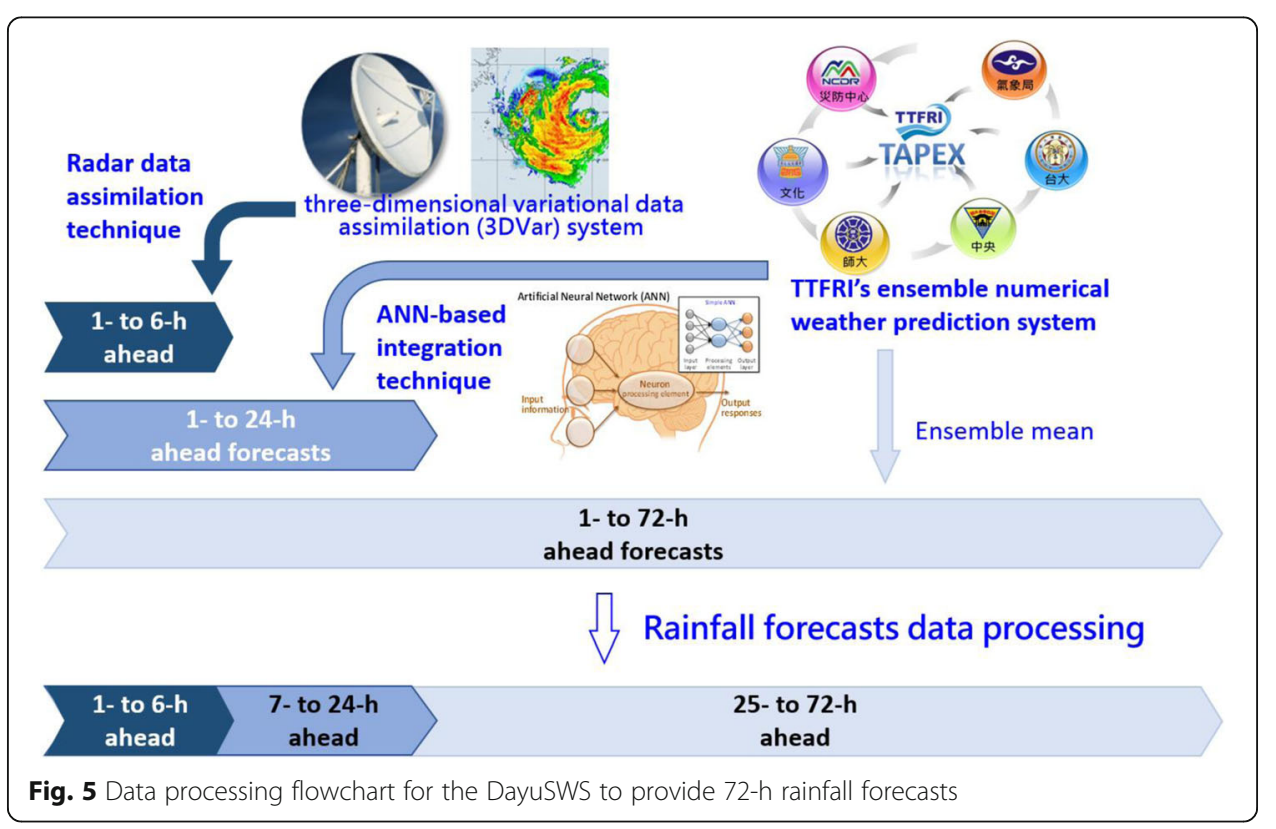


the accuracy of short-term rainfall forecasts (i.e., 1- to 6-h rainfall forecasts), realtime radar observation data are included. A radar data assimilation technique, namely the three-dimensional variational data assimilation (3DVar) system, is used. When the 3DVar system is used to rectify the modeled background errors, improved 1- to 6-h rainfall forecasts are obtained. Such forecasts are valuable for warning concerning floods due to convective storms. More details concerning the 3DVar system were provided by Sun et al. (2016). The proposed system uses the aforementioned rainfall forecasts as model inputs to generate flooding forecasts. The data processing flowchart is illustrated in Fig. 5. First, the ensemble mean of all the ensemble units in the TTFRI ensemble numerical weather prediction system is used to yield 1- to $72-\mathrm{h}$ rainfall forecasts. Among the obtained forecasts, 1 - to 24-h rainfall forecasts are then replaced by the improved forecasts yielded by the ANN-based integration technique. Finally, the 1- to 6-h rainfall forecasts are replaced by the improved forecasts yielded by the 3DVar system.

\section{Conversion level 1D-1D dual drainage model}

This section briefly describes the overall structure of the 1D-1D dual drainage model utilized in the proposed system. The proposed model was retrieved from the Storm Water Management Model (SWMM), which is an open-source model that has been widely adopted in many academic studies (Hsu et al., 2000; Chang et al., 2015). For the initial rainfall-runoff process, the rainfall information is first applied to the RUNOFF module of the SWMM to calculate the inflow discharges of manholes. Next, the information of the inflows at the manholes is directly used as input to the 1D-1D model to simulate the interaction between the below-ground storm sewer flows and the aboveground street flows (Fig. 6). After the 1D-1D model simulations, the surcharges from the manholes are considered as point sources to rapidly identify the high-risk surface inundation areas.

Governing equation of the RUNOFF module The RUNOFF module of the SWMM conceptualizes a catchment, which pertains to the input rainfall and output discharge, as a nonlinear reservoir. In this representation, the catchment has an inflow due to rainfall and an outflow due to evaporation and infiltration (Fig. 7). According to the

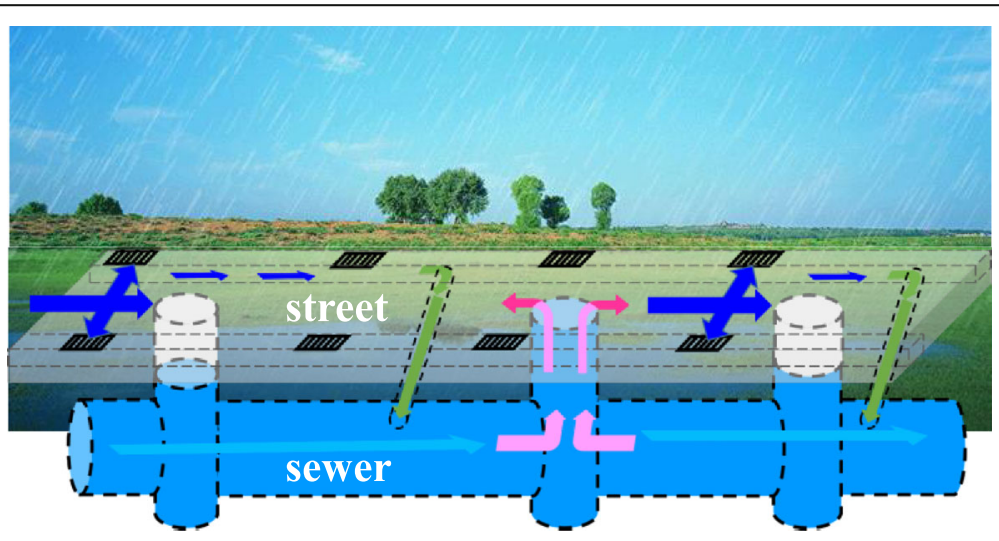

Fig. 6 1D-1D dual drainage model 


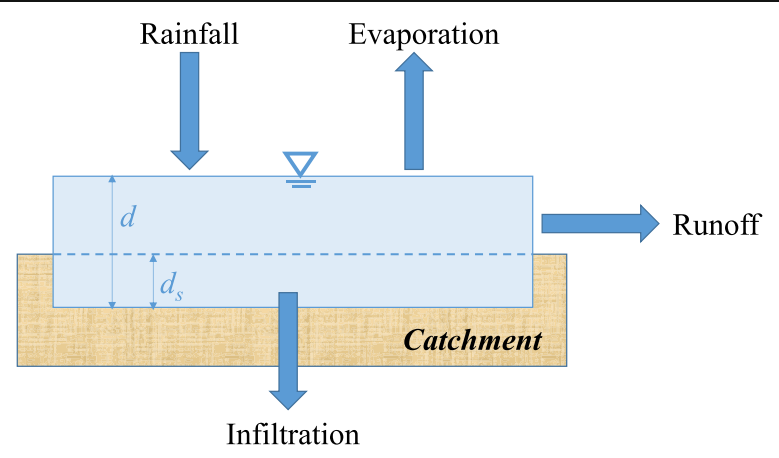

Fig. 7 Nonlinear reservoir model of a catchment

conservation of mass, the net change in depth $d$ per unit time $t$ between the inflow and outflow rates of the catchment is displayed in Eq. (1).

$$
\begin{aligned}
& \left\{\begin{array}{c}
\frac{\partial d}{\partial t}=i-e-f-q, \quad \text { if } d>d_{s} \\
\frac{\partial d}{\partial t}=i-e-f, \quad \text { else }
\end{array}\right. \\
& q=\frac{1.49 W S^{\frac{1}{2}}}{A n}\left(d-d_{s}\right)^{5 / 3}
\end{aligned}
$$

where $i$ is the rainfall rate, $e$ is the surface evaporation, $f$ is the infiltration rate, $q$ is the runoff rate (refer to Eq. (2)), $W$ is the average channel width, $S$ is the average slope of the catchment, $A$ is the surface area of the catchment, $n$ is a surface roughness coefficient, and $d_{s}$ is the storage depth.

Governing equation for the 1D-1D dual drainage model To obtain the flood routing in the sewer or street, the continuity equation is combined with the momentum equation, as shown in Eq. (3), to produce the average discharge.

$$
\frac{\partial Q}{\partial t}=2 U \frac{\partial A}{\partial t}+U^{2} \frac{\partial A}{\partial x}-g A \frac{\partial H}{\partial x}-g A S_{f}
$$

where $Q$ is the discharge in the sewer or street, $t$ is the time, $g$ is the gravitational acceleration, $A$ is the cross-sectional area of the sewer or street, $\mathrm{H}$ is the hydraulic head of water in the sewer or street, $S_{f}$ is the friction slope from Manning's equation, and $U$ is the velocity of water in the sewer or street. Details about solving Eq. (3) were provided by Rossman (2015).

Description of the model setup in Huawei Science Park The Huawei Science Park is an isolated urban drainage area. The 1D-1D dual drainage model in this area, as shown in Fig. 8, includes 88 subcatchments, 142 manholes, and 216 sewers and streets that collect the runoff and transfer the water to the detention ponds, which are located in the southwest corner of the area. 


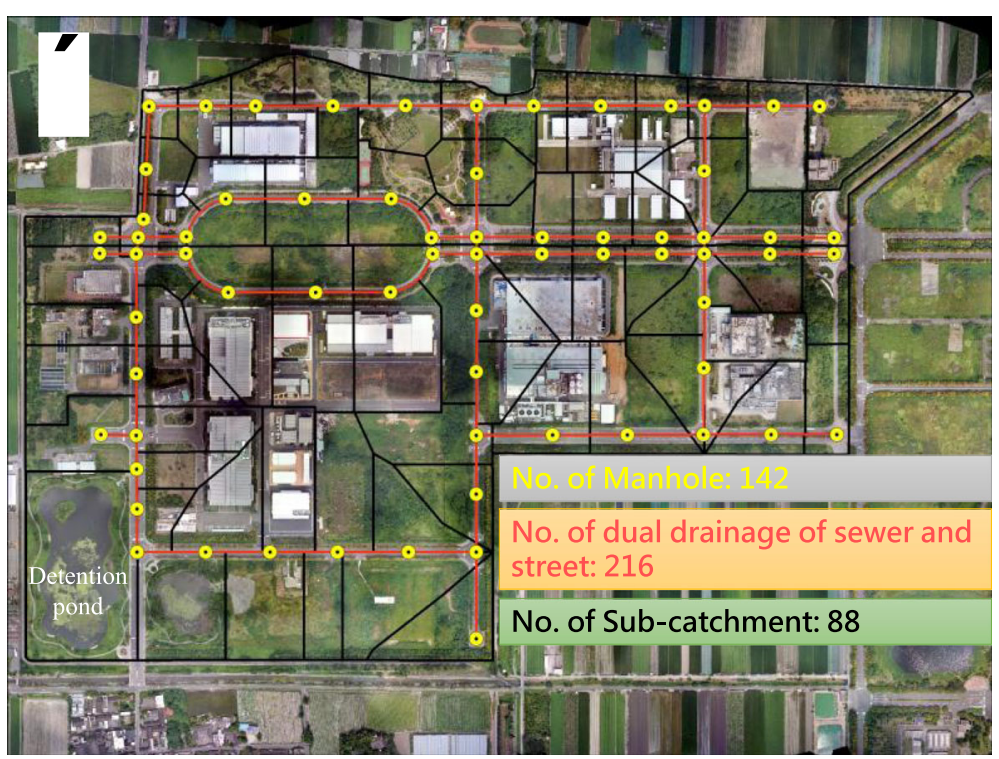

Fig. 8 Layout of the model setup in Huawei Science Park

\section{Case and discussion}

Figure 9 displays an example of an integrated system output of the DayuSWS. The connection level (01) provides users with information such as the current water level in the storm drainage system and real-time videos from two monitoring cameras. Three colors are used to provide warning information and to communicate with users concerning an upcoming situation. Green represents that "the situation is safe," yellow represents that "the drainage pipeline is $50 \%$ full," and red represents that "the drainage pipeline is $100 \%$ full and flood will occur shortly." The conversion level (02) provides location-specific information pertaining to the

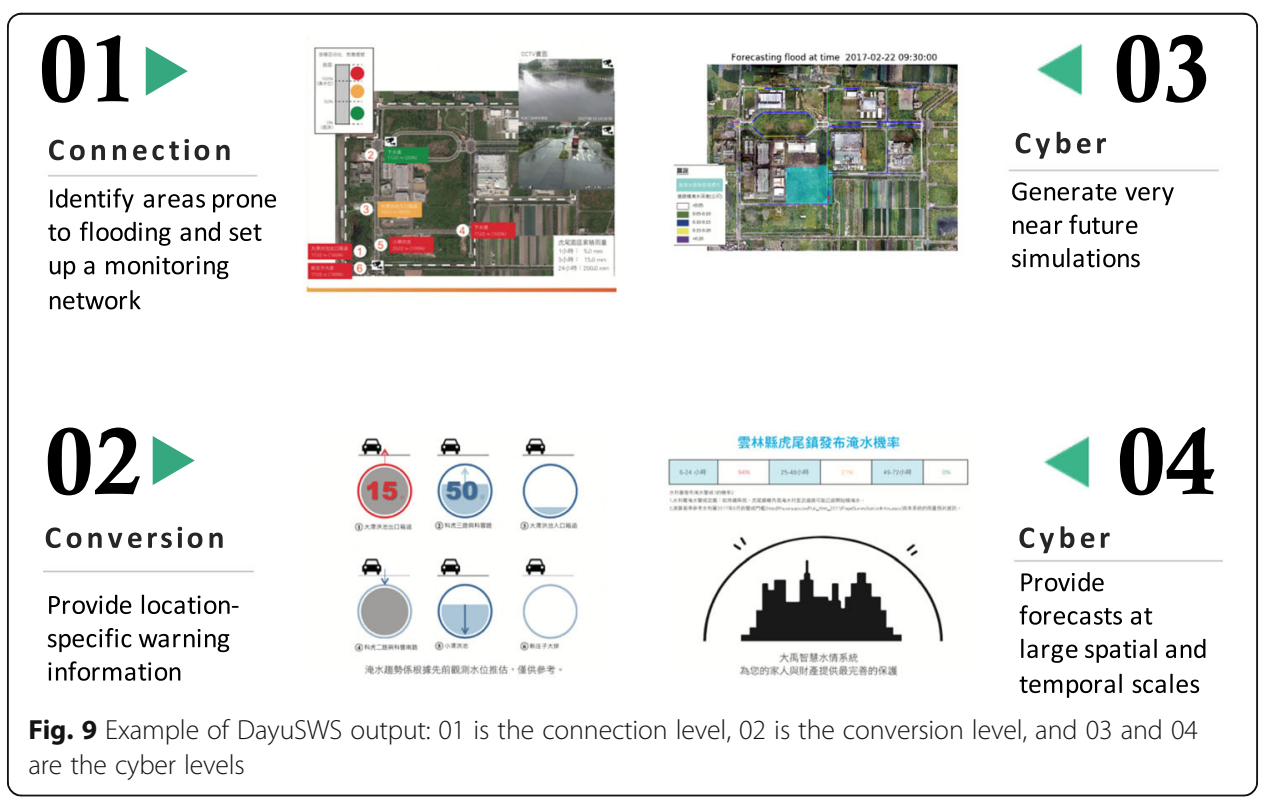


expected time in which the pipeline will be $100 \%$ full (red) or pipeline will be $50 \%$ full (blue). The results are visualized to facilitate the communication process. The cyber level 03 provides the subsequent 6-h forecast simulation results pertaining to the water level on roads and areas that can be flooded. The flooded area is only shown when the water level is higher than the curbs of the associated roads. The cyber level 04 provides flood forecast at the county level with a lead time of $72 \mathrm{~h}$ for precautionary purposes. The users can use this information to predict a disaster and identify its possible impact.

A few events occurred since the establishment of the DayuSWS in May 2017. The greatest event occurred on June 2, 2017 and was a high-rainfall event during the monsoon season (locally known as the Meiyu season). The Central Weather Bureau (CWB) reported that more than 100 locations in Taiwan experienced more than $230 \mathrm{~mm}$ of rainfall between early June 2 and early June 3, 2017. Some locations in northern Taiwan experienced more than $600 \mathrm{~mm}$ of rainfall during the same period. This rainfall event resulted in major flooding and mudslides. The study area experienced approximately $395 \mathrm{~mm}$ of rainfall in $24 \mathrm{~h}$. Figure 10 shows the radar observation obtained from the CWB and the rainfall distribution of the study area at the location of the Huawei rainfall gauge. The highest rainfall intensity of $49.5 \mathrm{~mm} / \mathrm{h}$ was observed on June 3 at $5 \mathrm{am}$. The period with the most severe rainfall was from 2 am to 8 am on June 3, with approximately $300 \mathrm{~mm}$ being accumulated in $6 \mathrm{~h}$.

The DayuSWS monitored the park area and provided the forecasts from $9 \mathrm{pm}$ on June 2, 2017. The results showed only a few bodies of standing water on the roads in the park but no significant floods. The system issued a warning message on June 3 at 7 am (Fig. 11). During the end of the event (Fig. 10), the storm drainage pipelines were almost 100\% full. Ponds A and B (Fig. 1) are designed to collect flood water for 50 years, and the storm sewage system is built to store water for 25 years. The warning that the pipelines were full indicated that the two detention ponds were almost full. If rainfall had continued, the park would be flooded. Nevertheless, a levee breach was found in the upstream portion of the study area (Fig. 12); thus, the flood water flowed to the upstream portion of the study area that contained farmlands, averting further damage to the downstream areas. During the event, the system provided accurate monitoring data and transformed the data to useful information at the connection and conversion levels. The

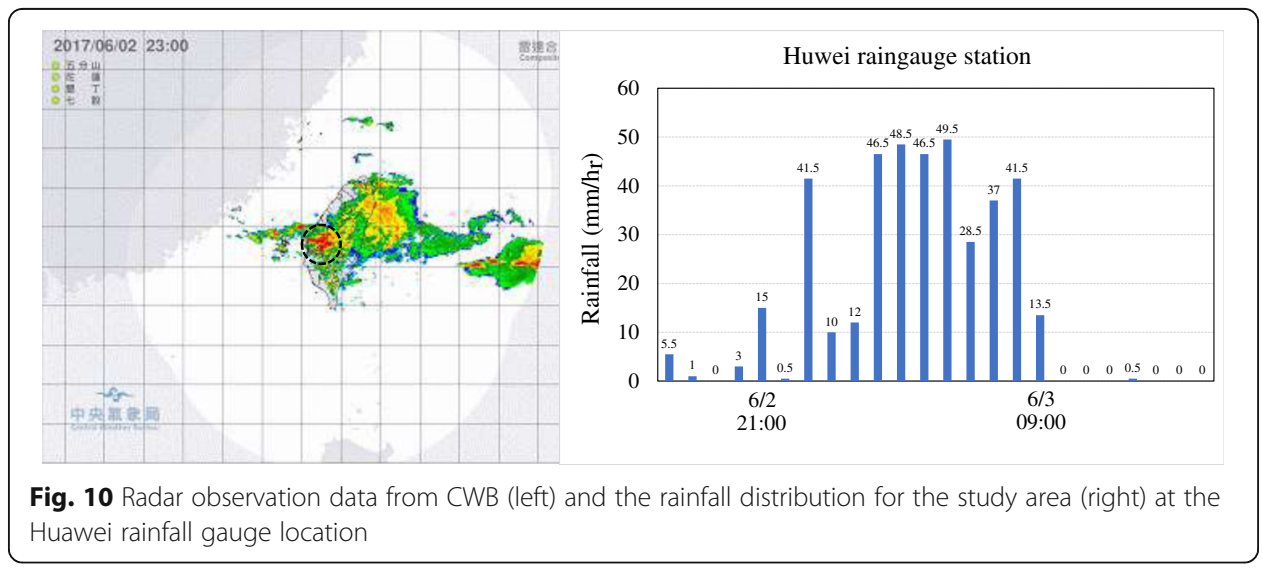




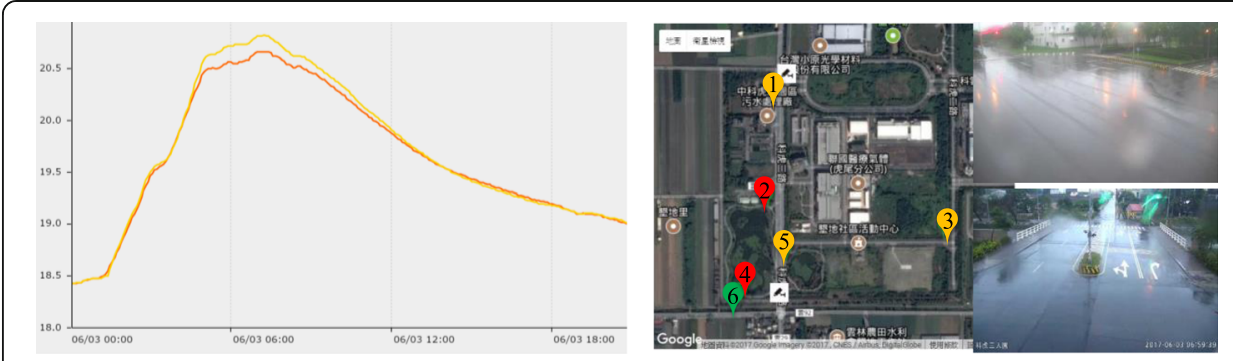

Fig. 11 Yellow and red lines are the locations 2 and 4, respectively. Both of them reached the red level of danger (water depth $=20.5 \mathrm{~m}$ ), which implies that the storm drainage pipeline is almost 100\% full

users could take immediate measures based on the information. If a forecast with a 6-h lead time was provided to users at the cyber level, they could plan emergency responses in advance to prevent or mitigate the impact of the predicted floods. The second greatest event that hit the study area was Typhoon Haitang on July 30, 2017. The accumulated rainfall was $211 \mathrm{~mm}$ from $7 \mathrm{pm}$ on July 30 to $7 \mathrm{pm}$ on July 31 . The highest rainfall hour was 4 am on July 31 . During the typhoon, only one warning message was issued, when the water level in the Hsinchuangzgi drainage was above the yellow level. However, the system predicted that no flooding would occur due to the typhoon, and no flood was witnessed. Thus, no damage was reported during Typhoon Haitang.

\section{Conclusions}

The study proposes an innovative CPS-based smart water system for providing real-time flood observations and forecasts with a 6-h lead time. The system integrates $\mathrm{AI}$ and IoT technologies to transform observed data to useful information. The system not only provides monitoring data to users but also enables them to actively take necessary measures to mitigate the impacts of floods. The system was implemented in a science park located in central Taiwan. A few events tested the capabilities of the system and proved the system's potential for future applications in disaster prevention and mitigation. However, the CPS concept is developed on

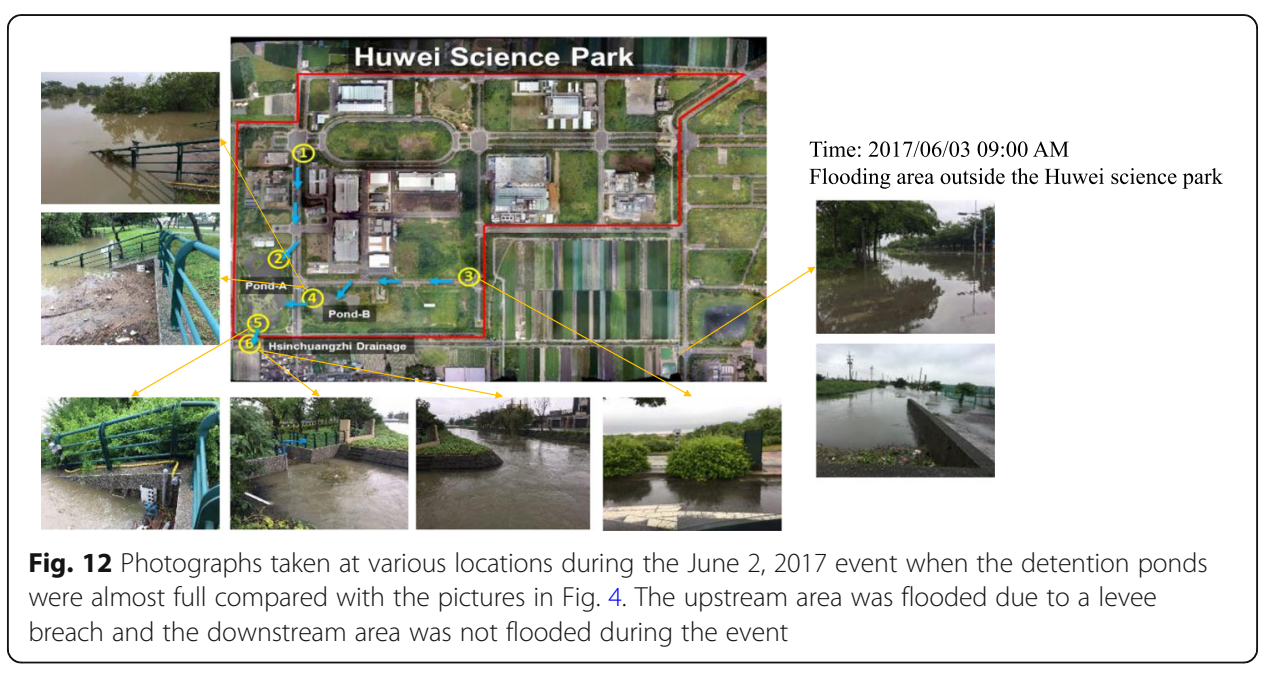


the basis of the $5 \mathrm{C}$ levels, and the system has implemented only the first three levels-connection, conversion, and cyber levels. The higher the number of levels is, the more added value is the system provides. The fourth and fifth levels, namely the cognition and configuration levels, were not discussed in the study. Further developments in these two levels will be conducted. For example, optimized operating rules for water pumps can be identified on the basis of future flood forecasts by using AI techniques. The optimized operation rules can mitigate or decrease the flooding area of a flood by using the minimum cost. This feature belongs to the cognition level. The water pumps can be automatically operated using the IoT through any optimized operating rule. Thus, the system can replace users and can perform an active role in taking necessary response measures; this belongs to the configuration level. Other applications such as providing optimized traffic route information by employing UAVs during a flood will also be included in the future applications. The CPS-based system has proved its potential to help in decisionmaking processes during a disaster. Future applications will offer more help to users and increase the efficiency of disaster relief. More applications of AI and IoT will be employed in next-generation hazard-related response systems.

\section{Acknowledgements}

The research was part of plan (grant no. 105f600191) funded by the Central Taiwan Science Park, Taiwan. The authors would like to thank its supporting.

Funding

The Central Taiwan Science Park (grant no. 105f600191).

Availability of data and materials

So far, the authors would not share research-related data or materials because we will do extended studies. We hope you can understand us. Many thanks!

\section{Authors' contributions}

The manuscript demonstrates a smart water system that integrates the concept of CPS and IOT. The purpose of this system is to provide more efficient and reliable flood forecasts and help decision-makers rapidly respond the threat of the flood. The system has been implemented in the Central Taiwan Science Park (CTSP). The experimental results revealed that the system could increase the response efficiency of the emergency operations center during a few extreme events in 2017. Thank you for your consideration of my work!. All authors read and approved the final manuscript.

\section{Competing interests}

The authors declare that they have no competing interests.

\section{Publisher's Note}

Springer Nature remains neutral with regard to jurisdictional claims in published maps and institutional affiliations.

\section{Author details}

${ }^{1}$ Taiwan Typhoon and Flood Research Institute, National Applied Research Laboratories, 11F, No. 97, Sec. 1, Roosevelt Rd, Taipei 100, Taiwan. ²Department of Civil and Disaster Prevention Engineering, National United University, No. 2, Lien Da, Nan Shih Li, Miaoli 360, Taiwan. ${ }^{3}$ Polytech Nice Sophia, University of Nice Sophia Antipolis, 06410 Biot, France.

Received: 27 November 2017 Accepted: 8 February 2018

/ Published online: 26 February 2018

References

Alemdar H, Leroy V, Prost-Boucle A, Pétrot F (2017) Ternary neural networks for resource-efficient Al applications. In neural networks (IJCNN), 2017 international joint conference on (pp. 2547-2554). IEEE

Augello A, Maniscalco U, Pilato G, Vella F (2016) Disaster prevention virtual advisors through soft sensor paradigm. In: Pietro G, Gallo L, Howlett R, Jain L (eds) Intelligent Interactive Multimedia Systems and Services 2016. Smart innovation, systems and technologies, vol 55. Springer, Cham

Chang TJ, Wang CH, Chen AS (2015) A novel approach to model dynamic flow interactions between storm sewer system and overland surface for different land covers in urban areas. J Hydrol 524:662-679

Eisner R (2014) Managing the risk of compound disasters. Chapter 5. In: Disaster risk management in Asia and the Pacific. Routledge, London, UK 
Hsiao LF, Chen DS, Kuo YH, Guo YR, Yeh TC, Hong JS, Fong CT, Lee CS (2012) Application of WRF 3DVAR to operational typhoon prediction in Taiwan: impact of outer loop and partial cycling approaches. Weather Forecast 27(5):1249-1263

Hsiao LF, Yang MJ, Lee CS, Kuo HC, Shih DS, Tsai CC, Wang CJ, Chang LY, Chen DYC, Feng L, Hong JS, Fong CT, Chen DS, Yeh TC, Huang CY, Guo WD, Lin GF (2013) Ensemble forecasting of typhoon rainfall and floods over a mountainous watershed in Taiwan. J Hydrol 506:55-68

Hsu MH, Chen SH, Chang TJ (2000) Inundation simulation for urban drainage basin with storm sewer system. J Hydrol 234:21-37

Lee J, Bagheri B, Kao HA (2015) A cyber-physical systems architecture for industry 4.0-based manufacturing systems. Manufacturing Letters 3:18-23

Lopez-Trujillo D (2010) Real time flood alert system (RTFAS) for Puerto Rico. US Department of Interior, US Geological Survey

Mahul O (2017) Toward a regional approach for disaster risk finance in Asia. ICRM Symposium 2017, 3-4 August 2017, Dermatol Sin

Monostori L (2003) Al and machine learning techniques for managing complexity, changes and uncertainties in manufacturing. Eng Appl Artif Intell 16(4):277-291

Monostori L, Kádár B, Bauernhansl T, Kondoh S, Kumara S, Reinhart G, Sauer O, Schuh G, Sihn W, Ueda K (2016) Cyberphysical systems in manufacturing. CIRP Annals-Manufacturing Technology 65(2):621-641

Rho S, Vasilakos A, Chen W (2016) Cyber physical systems technologies and applications. Futur Gener Comput Syst 56 : 436-437

Rossman LA (2015) Storm water management model. User's manual Ver. 5.1. U. S. Environmental Protection Agency

Sun JZ, Wang HL, Tong WX, Zhang Y, Lin CY, Xu DM (2016) Comparison of the impacts of momentum control variables on high-resolution variational data assimilation and precipitation forecasting. Mon Weather Rev 144(1):149-169

Thielen J, Bartholmes J, Ramos MH, de Roo A (2009) The European flood alert system - part 1: concept and development. Hydrol Earth Syst Sci 13:125-140

Wu MC, Lin GF (2017) The very short-term rainfall forecasting for a mountainous watershed by means of an ensemble numerical weather prediction system in Taiwan. J Hydrol 546:60-70

Wu MC, Lin GF, Hwang LR, Chen DYC, Chiang CC, Wang YC (2016) Optimal integration of the ensemble forecasts from an ensemble quantitative precipitation forecast experiment. Procedia Eng 154:1291-1297

Yang TH, Yang SC, Ho JY, Lin GF, Hwang GD, Lee CS (2015) Flash flood warnings using the ensemble precipitation forecasting technique: a case study on forecasting floods in Taiwan caused by typhoons. J Hydrol 520:367-378

Submit your manuscript to a SpringerOpen ${ }^{\odot}$ journal and benefit from:

- Convenient online submission

- Rigorous peer review

- Open access: articles freely available online

- High visibility within the field

Retaining the copyright to your article

Submit your next manuscript at $>$ springeropen.com 